\title{
Electro-Mechanical Model for Understanding the Operation and Dynamic Behavior of a Micro-Grid: a case study in Tanzania
}

\author{
Stefano Mandelli, Marco Merlo \\ Politecnico di Milano \\ Dep. of Energy \\ Milan, Italy \\ stefano.mandelli@polimi.it \\ marco.merlo@polimi.it
}

\author{
Elisabetta Tedeschi \\ NTNU \\ Dep. of Electric Power Engineering \\ Trondheim, Norway \\ elisabetta.tedeschi@ntnu.no
}

\author{
Marta Molinas \\ NTNU \\ Dep. of Engineering Cybernetics \\ Trondheim, Norway \\ marta.molinas@ntnu.no
}

\begin{abstract}
This paper introduces the project Energy4Growing which aims to set up a hybrid micro-grid to supply power to a school in rural Tanzania. It describes the results of the early project actions which concerned: (i) monitoring of the actual school power supply system; (ii) first step development of a new model which addresses the simulation of the electro-mechanical operation and dynamic behavior within an off-grid power supply system with respect to perturbation in the power injections and consumptions. In particular it focuses on the new model which has the capability to address: (i) $V$ and $F$ trends analysis over medium term period by means of simplified electrical models of power sources and power electronics, (ii) the analysis of different control strategies and their consequence on $V$ and $f$ trends, (iii) the effects of control strategies on the energy performances of particular components such as battery pack or dump loads. This new approach is also applied by modelling the actual school power supply system with MATLAB SimPowerSystem.
\end{abstract}

Keywords-off-grid system, renewable energy, rural electrification, data meter, simulation.

\section{INTRODUCTION}

During the last decade a lot of efforts have been made to promote access to electricity for those people living in un-electrified areas of Developing Countries (DCs). Nevertheless, nowadays about 1.3 billion people still lack access to electricity and about $82 \%$ of these live in rural areas of DCs [1]. Moreover, when power supply is available in these areas, reliability is often a serious issue and long outages occur several days per month [2]. Especially in rural areas, low electrification rates and poor reliability of the power supply is a burden in the process of local development. Indeed this situation prevents satisfying the energy needs of households, health and education services, and of productive activities more effectively and efficiently [3].
Besides being a tool to fight poverty and a lever for development, increasing electrification rates and improving the power supply service could address a huge potential market of new consumers. Nevertheless the electrification process is proceeding slowly and according to the IEA projections, in 2030, still about 1 billion people in DCs will lack access to electricity [1]. The evident economic constraints and the lack of appropriate and replicable technical solutions are major reasons that contribute to hindering the process of electrification. In this regard, R\&D activities in off-grid Renewable Energy (RE) and hybrid power systems - which are often the most appropriate option for rural electrification [4]-[7] - should also focus on solutions that (i) can easily adapt to very different implementation conditions and reduce capital costs, and (ii) can have outputs for uses in the developed world thus expanding market opportunities.

In this context, the project Energy4Growing (E4G), promoted by a research group of the Politecnico di Milano, aims at studying, developing and setting up an off-grid power system to supply electricity to the school of Ngarenanyuki, a rural village in Northern Tanzania. Specifically, the project investigates a hybrid micro-grid architecture suitable to interface RE technologies and energy needs in the most reliable way while exploiting advanced regulations and control techniques. The hybrid micro-grid will combine the power generation systems already available in the school (i.e. a run-off-river microhydropower (MHP) plant and a back-up petrol generator) with new installations of PV panels and lead-acid battery pack together with an Interface Converter.

This paper describes the results of the early project actions which concerned (i) metering of the functioning of the actual school power supply system, and (ii) the development, and setting up of a new model for the simulation of the functioning of off-grid power supply systems. In particular, it focuses on describing the first 
step development of the new model useful to simulate the electro-mechanical operation and dynamic behavior within an off-grid power supply system with respect to perturbation in the power injections from generators and loads. An example based on modeling with MATLAB SimPowerSystem of the current configuration of the runoff-river MHP plant and employing the metered data exemplifies the setup and potential of this approach. Our aim in developing this model is to contribute in improving the process design of off-grid power supply systems in order to facilitate the replicability of these interventions for rural electrification actions.

\section{THE ENERGY4GROWING PROJECT}

In addition to $R \& D$ interests, the $E 4 G$ project aims at improving the power supply service of the secondary school of the Ngarenanyuki village (Fig. 1). Here 460 students attend the school and $85 \%$ of them are resident in the school facilities which include classrooms, offices, dormitories, library, kitchen, teachers' houses, etc. .
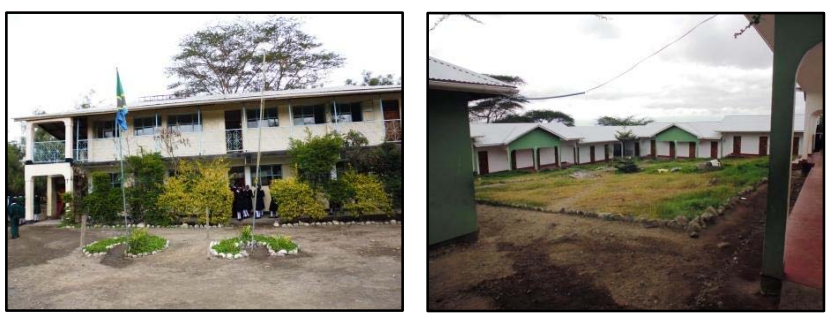

Fig. 1 Ngarenanyuki secondary school. Arusha, Tanzania

\section{A. Present school power supply systems}

The main power source of the school is a run-off-river MHP plant based on a $3.2 \mathrm{~kW}$ Banki turbine coupled with 1-phase brushless synchronous generator $(230 \mathrm{~V}, 50 \mathrm{~Hz})$. The turbine always works at full capacity according to the stream flow and the frequency regulation is based on a 4 $\mathrm{kW}$ dump load which dissipates the excess power into the air (Fig. 2). The water flow to the turbine is diverted from a stream which is managed by local farmers. Therefore, water availability is highly variable during the day and according to the season. This requires having an operator of the MHP plant who manually regulates the turbine distributor in order to keep the water pressure at proper level in the penstock.
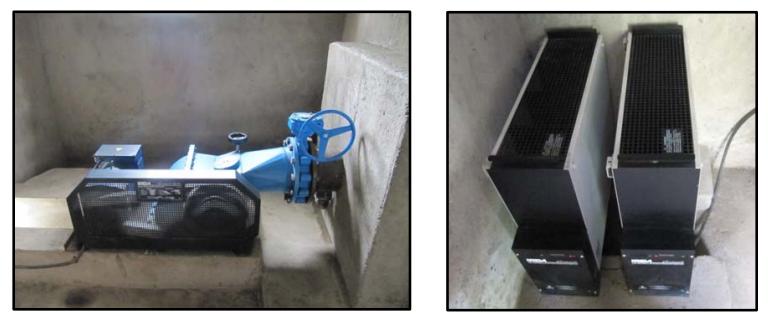

Fig. 2 Banki turbine and generator - Dump loads
Owing to the unpredictability of the available water supply and hence to the discontinuity of the power produced via the MHP plant, the school also installed two back-up systems:

- a battery pack of 8 x $100 \mathrm{Ah} / 12 \mathrm{~V}$ Chloride Exide batteries that can be charged via the MHP plant thanks to a $2.4 \mathrm{~kW}$ charge inverter (Fig. 3);

- a $5 \mathrm{~kW}$ petrol generator which is manually switched on and off. Indeed, owing to the high running costs, it is used when the MHP plant is off and the battery packs are discharged and only for special reasons (i.e. use of photocopy machine, school celebrations, etc.).
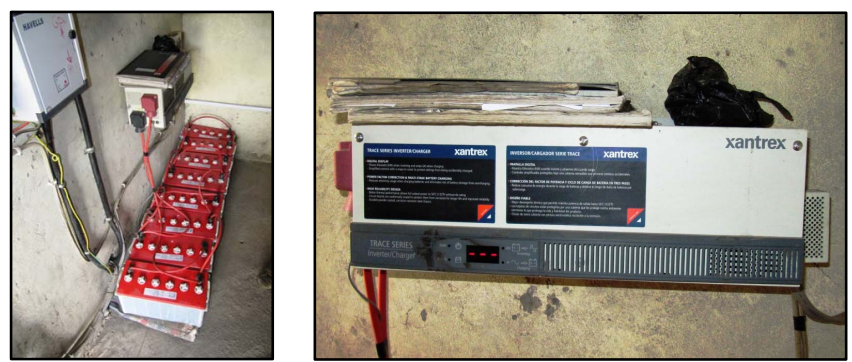

Fig. 3 Battery pack and charge inverter coupled with the AC system

The power supply is managed in the control room by means of a toggle switch that permits the choice of the power source to be used, while a group of breakers permits specific loads to be connected/disconnected (Fig. 4). At the moment, the operation of the system is managed by an operator who checks the proper working conditions of the Banki turbine, selects the power source to be employed and connects/disconnects the loads. Despite the operator (not being available h24) and the school staff having gained a fair practical experience as regards the system functioning, the system management is far from being effective and efficient, and hence several blackouts occur.

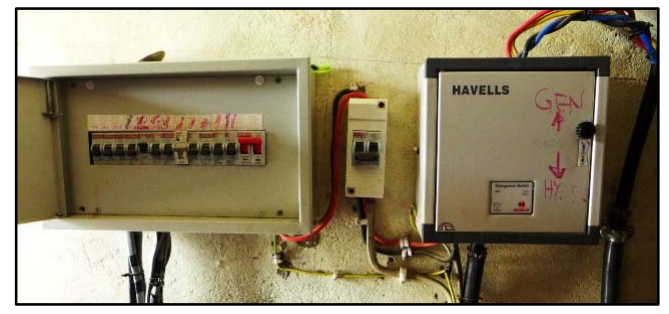

Fig. 4 Control panels of the main AC system: loads breakers (left), master switch (center), toggle switch (right)

\section{B. School loads and consumption}

Currently the number and type of the electric devices available in the school are determined by the limited generators and storage capacities. In the same way, the energy source availability, determined by the farmer water use, strongly influences the consumption pattern day by day and hour by hour. Therefore it is difficult to assess the 
existing demand both in term of daily consumptions and load profiles. Moreover this situation suggests that the consumption pattern may increase dramatically following changes in power generation capacities. Nevertheless having information about the energy consumptions and load profiles of the user is mandatory in order to perform properly energy analyses as well as power stability analyses of off-grid power supply systems. Therefore, among the initial activities of the project, a detailed analysis of the school loads was carried out. Two steps compose this analysis: (i) data collection about the existing loads and load profile estimate at office level; (ii) metering of the main electrical quantities during system functioning.

TABLE 1: EXISTING LOADS IN THE SCHOOL ACCORDING TO THE SURVEY CARRIED OUT BY SCHOOL STAFF

\begin{tabular}{lllrr}
\hline & Location & Appliance & Unit & W \\
\hline 1 & Classrooms & Light & 40 & 9 \\
2 & Staff office & Light & 19 & 9 \\
3 & Staff office & Photocopy machine & 1 & 1500 \\
4 & Staff office & Printer & 1 & 150 \\
5 & Staff office & Desktop & 1 & 400 \\
6 & Staff office & Laptop & 2 & 80 \\
7 & School/staff houses & TV & 7 & 250 \\
8 & Staff house & Light & 35 & 9 \\
9 & Staff house & Laptop & 9 & 80 \\
10 & Library & Light & 9 & 9 \\
11 & Dormitories & Light & 71 & 9 \\
12 & Shop and canteen & Light & 3 & 9 \\
13 & Shop and canteen & Fridge & 1 & 80 \\
14 & Borehole & Pump & 1 & 700 \\
15 & Security lights & Neon & 43 & 40 \\
\hline
\end{tabular}

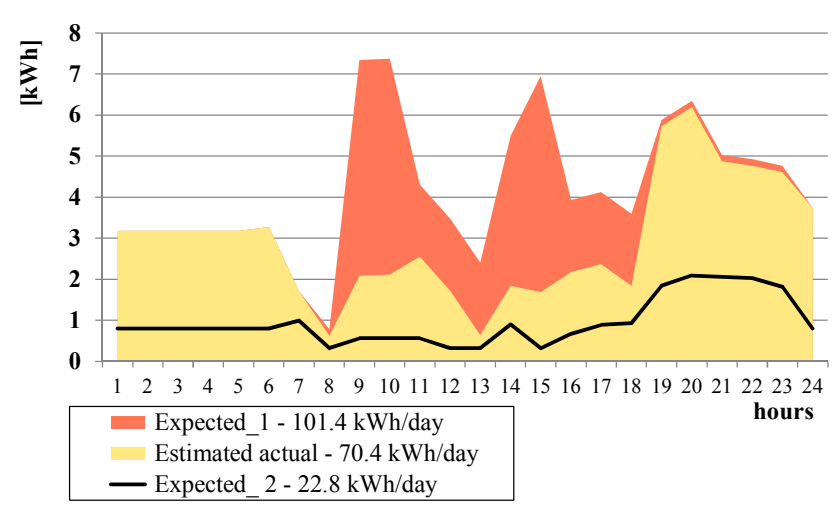

Fig. 5 Load profile estimates for the actual consumption pattern

Concerning the first step, Table 1 shows the existing loads in the school, while Fig. 5 shows the resulting load profiles estimated at office level:

- the yellow profile refers to an estimate of the actual load profile obtained by considering the existing loads and by assuming appliances functioning data in accord with the information provided by the school staff;

- the red profile refers to an estimate of the expected load profile (ex-post the project intervention) in accord with the information provided by the school staff which considers the use of new further appliances (i.e. laptops, washing machine, iron, etc.);

- the black solid line refers to an estimate of the expected load profile (ex-post the project intervention) which has been developed in order to properly match the daily energy consumed with the available daily generation from the MHP and PV plants. This analysis was carried out due to the clear overestimate of the actual energy consumption (i.e. yellow profile, $\sim 70 \mathrm{kWh} /$ day). The matching of the generation profile and the load profile was accomplished by an energy analysis made with the software HOMER Energy [8], and specifically by reducing the functioning data, and in some cases also the units, of the existing loads in the school.

This first step in the school loads analysis allowed the gathering of early information about the actual situation of the power supply service and proper feedbacks to the school staff to be provided as regards the expectations for the project intervention. Moreover, it suggested the second step in the school loads analysis should be carried out in order to gather more detailed data to proceed properly in the design process of the hybrid micro-grid.

For this second step a smart-meter apparatus was installed on-site on the load side of the control panels to measure and to store load data locally about: active and reactive power flows, frequency, voltage and power factor. The specific purposes of this activity are: (i) to understand better the actual consumption pattern (i.e. daily consumptions and load profiles), and (ii) to gather data in order to allow the analysis of the dynamic behavior of the actual power supply system, the Banki turbinesynchronous generator and the dump loads in particular.

Here a number of early results are reported as regards the on-site metering activity that is currently on-going and which refers to about 100 days from June to September 2014 with 15 minutes average data storing. Fig. 6 shows the discrete probability distribution of the daily consumption. Fig. 7 reports an aggregate analysis of the metered load profiles. Specifically, the red (green) solid line represents the minimum (maximum) metered values throughout length of the day, and the blue solid line represents the average values of the metered ones throughout length of the day. Fig. 8 shows the discrete probability distribution of the measured system frequency. Some remarks can be made describing these data:

- the daily energy consumptions range from a few $\mathrm{kWh}$ to about $25 \mathrm{kWh}$ : this suggests a high variability of the water source availability on a daily basis;

- at each hour of the day the power loads ranges from 0 $\mathrm{W}$ to values above $1.5 \mathrm{~kW}$. This suggests a highly irregular water source availability on an hourly basis rather 
than inconsistent consumption habits which, on the contrary, tend to be regular;

- the frequency of the power supply proves to be quite stable at $50 \mathrm{~Hz}$. The right end of the probability distribution $(>50 \mathrm{~Hz})$ is a consequence of the nominal frequency of the petrol generator, while the left end of the probability distribution $(<50 \mathrm{~Hz})$ is a consequence of the transient dynamics of the system during turbine overload.

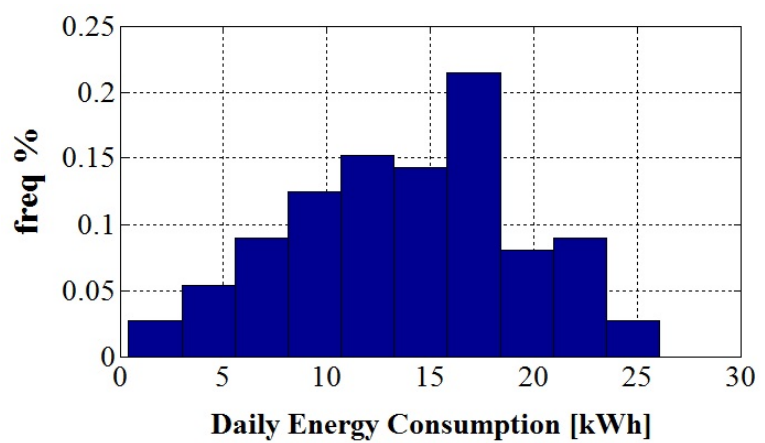

Fig. 6 Discrete probability distribution (freq. \%) of daily consumptions

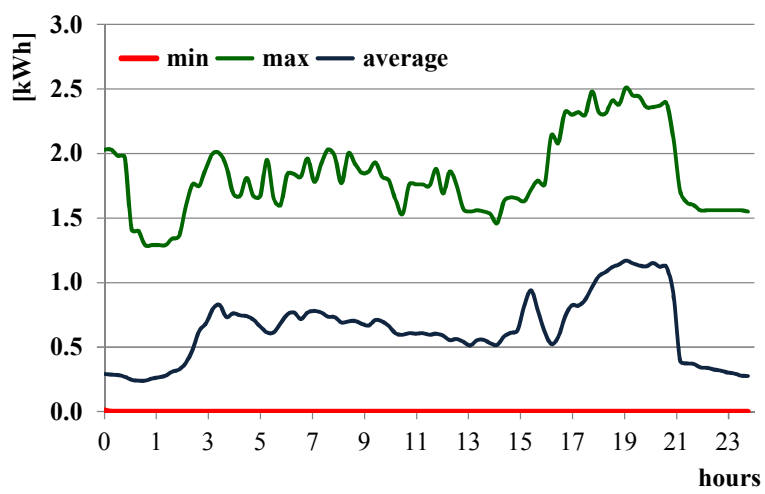

Fig. 7 Aggregate analysis of load profiles

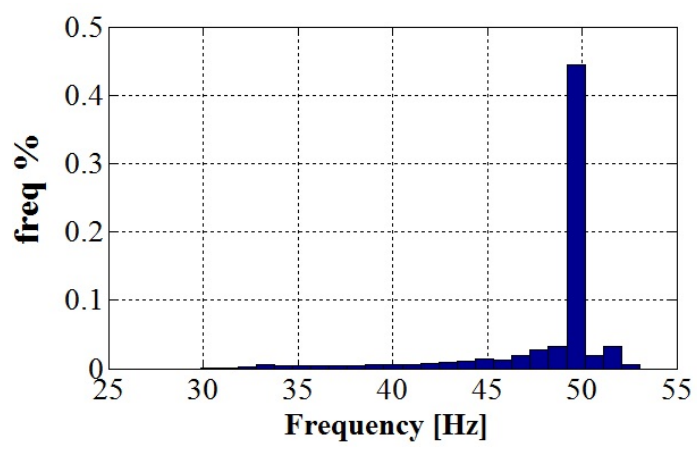

Fig. 8 Discrete probability distribution (freq. \%) of the power supply frequency

\section{ADDRESSING OFF-GRID POWER SUPPLY SYSTEM DESIGN WITH ENERGY AND POWER STABILITY ANALYSES}

With respect to the $\mathrm{E} 4 \mathrm{G}$ project, there are two main project purposes behind setting up the hybrid micro-grid: (i) improving the power supply service of the school by increasing the generating capacity and by adopting an Energy Management System capable of effectively and efficiently integrating the different power sources; (ii) developing procedures and tools to be employed in the process design of off-grid power supply systems in order to facilitate the replicability of these interventions for rural electrification actions. This paper focuses on the latter.

In this specific case, but generally when dealing with off-grid systems combining different power sources and power electronics interfaces, the design process of the system is not straightforward. In this regard, some issues can be highlighted considering the actual power supply system of the school and the proposed micro-grid.

Currently, during the system functioning, the dump loads keep the balance between the generation and the consumption sides while assuring the stability at $50 \mathrm{~Hz}$ of the power supply. On the other hand, the stability is preserved to the detriment of dissipated energy on air by the dump loads.

The proposed architecture of the hybrid micro-grid provides for the parallel functioning of (i) the turbine/synchronous generator/dump load group and (ii) the PV/battery pack apparatus. This solution can limit the dissipated energy; nevertheless, it brings about issues as regards the control of the system stability as well as the life-time performances of the battery pack.

Indeed the battery pack can be operated in order to absorb part of the power on the dump load thus minimizing the dissipated energy and increasing the system efficiency. On the other hand this may increase the charge/discharge cycles of the battery pack (probably with shallower but more frequent cycles) thus decreasing its lifetime. Therefore it is necessary to analyse the functioning conditions of the battery pack, as regards the energy flows, in order to optimize the system control logics aiming at the longest life-time.

Nonetheless, the control logics that coordinate the operations between the battery pack and the dump loads can compromise the system stability. Indeed dealing with the energy flows in order to optimize the battery pack/dump loads functioning can come into conflict with the energy flows control for the proper system frequency regulation. Therefore it is necessary to analyse the control logics with regard to the system components reaction times, the rates of change in the power flows that can occur during the system functioning, the system inertia, etc. 
In the scientific literature two main types of analyses are typically carried out in order to address these issues: energy analyses and power stability analyses:

- concerning energy analyses (e.g. [9]-[14]), the objective is to identify the main component sizes (i.e. rate power of generators and storage capacity) with an energy planning and/or a techno-economic approach. These analyses study the system performances throughout its life-time considering the local conditions and constraints. They are typically based on the steady-state solution of the energy balance (i.e. Joule or Watt-hour) between energy sources and consumer loads and considering the features of the system components. Different accuracy in the analyses mainly results from the length of the time-step the balance is solved for the degree of detail in the load/energy source data, in the mathematical modeling of the system components, and from the approach employed to look for the optimal solution. Usually time-step can vary from day-to-day to one-minute and analyses are performed throughout a year. A typical tool that embraces the main features of the energy analyses is HOMER Energy (e.g. [15]-[17]). Recently multi-objective optimizations and multi-criteria decision making have been increasingly employed in order to embrace also environmental and social parameters in the planning and/or feasibility analyses (e.g. [18]-[21]);

- concerning power stability analyses ([22]-[25]), the main objective is to address the study of power system stability employing electrical quantities (e.g. current and voltage) and verifying the proper functioning of each single component and the interactions among them. These analyses are based on circuit models of the components and on the solving of the related equations within the continuous time-domain. They are typically carried out for short intervals (from few to tens of seconds) in order to study the developments of the monitored electrical quantities and to verify the proper system functioning under particular circumstances. When the issue of the power supply quality is addressed, voltage and frequency ( $V$ and $f$ ) values are the key quantities analyzed.

In this framework, and given our experience with the E4G project, it will be important to address some important aspects of the design process of off-grid systems that which are not appropriately addressed both by energy and power stability analyses:

- concerning energy analyses: (i) even when electrical quantities are employed in system components modelling, systems are studied with steady-state numerical simulations and hence trends of $V$ and $f$ are never analyzed, (ii) even when considered, dispatch strategies focus on the energy balance without considering the consequences they have on system control and hence on $V$ and $f$. These aspects can affect the size as well as the lifetime of the components especially when systems include rotating machines together with RE generators with power converters and electrochemical storage;

- concerning power stability analyses, they do not provide elements to optimize the sizes of the main components as regards system life-time and they are too heavy when addressing issues that occur over longer periods (i.e. battery charge/discharge cycle, system control strategies, etc.).

\section{NEW APPROACH FOR ELECTRO-MECHANICAL OPERATION AND DYNAMIC BEHAVIOR ANALYSIS}

In order to address the above mentioned issues, in this paper a new approach to system modelling is introduced that aims at providing analyses in order to balance the limits and integrate the results of the already available energy and power stability approaches. The approach adopts classical mathematical models for generators and load representation; nevertheless, the adoption of such models for an off-grid power supply system design instead of classical energy variable models is, in the authors' opinion, an innovative content.

The objective of the new approach is to develop offgrid power supply system simulation models capable of:

- working over medium term period (i.e. days) with typical time-steps of power stability analyses;

- embracing simplified electrical models of power sources and power electronics in order to address at least $V$ and $f$ trends analysis;

- embracing simplified models of system control units in order to address the analysis of different control strategies and their consequence on $V$ and $f$ trends;

- considering the effects of the previously-mentioned aspects on the performances of particular components such as battery pack or dump loads.

Actually, the goal could be summarized in the development of a model library useful to simulate the electro-mechanical operation and dynamic behavior within an off-grid system (based on both static converter interfaced and rotating machines), with respect to perturbation in the power injections from load and generators.

Hereafter we detail the description of the model development for a synchronous generator then we briefly introduce the loads model and the static machines model.

The dynamic behaviour of a 2-poles synchronous generator can be exhaustively analysed by the $7^{\text {th }}$ order model in the Park variables which is made up of the following equations (with reference to Fig. 9):

$$
\begin{aligned}
& p \cdot \phi_{d}=V \cdot \sin (\delta)-R \cdot i_{d}+\omega_{m} \cdot \phi_{q} \\
& p \cdot \phi_{q}=V \cdot \cos (\delta)-R \cdot i_{q}-\omega_{m} \cdot \phi_{d}
\end{aligned}
$$




$$
\begin{aligned}
& p \cdot \phi_{F}=V_{F}-R_{F} \cdot i_{F} \\
& p \cdot \phi_{D}=-R_{D} \cdot i_{D} \\
& p \cdot \phi_{Q}=-R_{Q} \cdot i_{Q} \\
& p \cdot \omega_{m}=\left(C_{e}-C_{r}\right) / J \\
& p \cdot \delta=\omega_{m}-\omega
\end{aligned}
$$

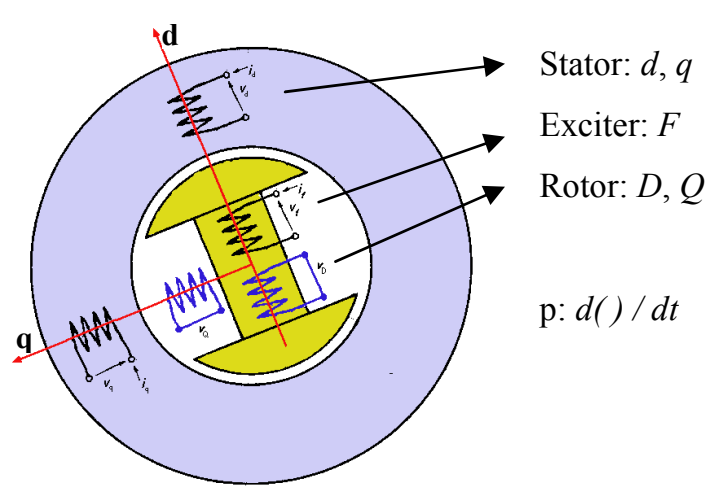

Fig. 9 Synchronous generator model w.r.t. Park transformation

In accord with the previously mentioned targeted features of the new approach the $7^{\text {th }}$ order model is simplified by considering electro-magnetic dynamics faster than mechanical ones, consequently electromagnetic variables are supposed with steady-state behavior.

Consequently the differential equations (1) to (5) become algebraic equations since the time derivative of the magnetic flux (i.e. $p \cdot \phi$ ) are assumed non-existent. Therefore the simplified electro-mechanical model of the synchronous generator is based on equations (6) and (7) (i.e. the swing equation) that account for the change in the angular velocity $\left(p \cdot \omega_{m}\right)$ of the generator given the engine and load torques $\left(C_{e}-C_{r}\right)$ and according to the system inertia $(J)$. Finally, according to the new approach the synchronous generator can be modelled as an ideal voltage source driven by the swing equation and hence accounting for changes in power injections from load and engine that results in change in angular velocity (i.e. system frequency).

In modelling the loads and the static machines (i.e. inverters) it is considered that the electro-magnetic dynamics are faster than the mechanical dynamics, and hence the related variables evolve according to a steadystate behavior. Consequently loads and inverters can be modelled with ideal controlled sources as regards: the resulting system frequency from the swing equation, and algebraic equations as regards the power injections.

As already highlighted, this is a first step development of the new model and it is the base for further on/going refinements both in the energy-oriented and power stability-oriented directions. Moreover, it is important to highlight how these assumptions are consistent with the information available in DCs, i.e. the adoption of more detailed models does not lead to a more complete/reliable analysis due to the lack of information about generators, loads etc. Consequently, the approach proposed is designed in order to fit with the DCs scenarios.

\section{MODEL OF THE ACTUAL SCHOOL POWER SUPPLY SYSTEM}

The first implementation and early results of the new approach is described in the following by an example based on the modelling with MATLAB SimPowerSystem of the current configuration of the run-off-river MHP plant at Ngarenanyuki school. In particular, we deal with the actual school power supply system configuration in order to model and analyse the dump load functioning. Indeed, this is the first step towards the analysis and optimization of the interactions between dump loads and battery pack. The model development was carried out by means of collaboration between Politecnico di Milano and NTNU and includes models of: (i) the synchronous generator, (ii) the user loads and (iii) the dump loads (Fig. 10).

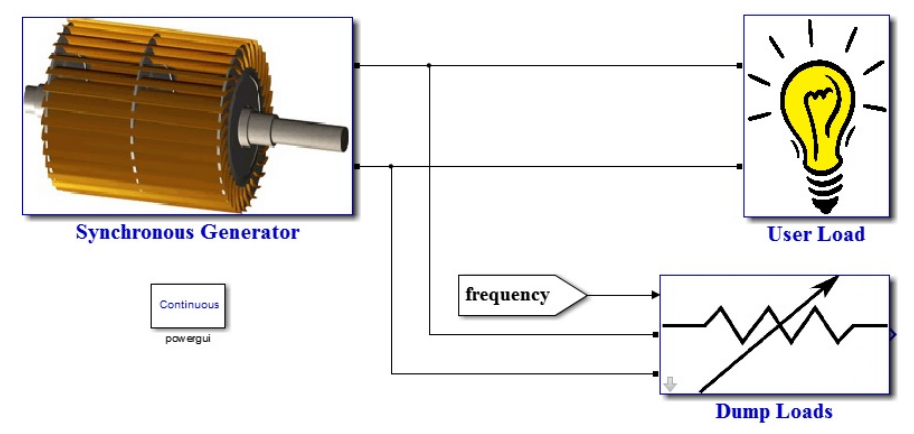

Fig. 10 SimPowerSystem building blocks for actual school power system modelling

According to the previous descriptions, they are modelled as follows:

- an ideal controlled voltage source represents the synchronous generator. The input signal which drives the generated voltage is given by eq. 8 where the angular velocity $\omega$ results from the swing equation (eq. 9):

$$
\begin{aligned}
& V=230 \cdot \sqrt{ } 2 \cdot \sin (\omega \cdot t) \\
& J \cdot \omega \cdot p \omega=P_{\text {gen }}-P_{\text {load }}-P_{\text {dump }}
\end{aligned}
$$

- an ideal controlled current source represents the user loads. The input signal which drives the generated current is given in eq. 10 where the RMS current value $\left(I_{\text {load }}\right)$ is given by eq. 11 and the angular velocity $\omega$ results from the swing equation:

$$
\begin{aligned}
& I=I_{\text {load }} \cdot \sqrt{ } 2 \cdot \sin (\omega \cdot t) \\
& P_{\text {load }}=230 \cdot I_{\text {load }} \cdot \cos (\phi)
\end{aligned}
$$


- the dump loads dissipate the excess energy generated by the turbine-generator group, which always works at full load. Keeping the electrical load constant on the generator, the angular velocity of the turbine-generator group (i.e. the frequency) is also automatically kept constant. At the school, a pair of $2 \mathrm{~kW}$ dump loads is installed and each of them has 15 regulating steps of $133 \mathrm{~W}$. Therefore, the regulation curve can be approximately compared to a straight line (Fig. 11). Moreover, as for the recovery time, the dump loads regulator switches from 0 to $100 \%$ of the regulated power in approximately $150 \mathrm{~ms}$ (Fig. 12) [26]. A $\mu$ p-controlled electronic board manages the dump loads by means of a PID control. Hence the plant frequency changes affect the feedback in function of the entity, duration and speed.

Accordingly, in the SimPowerSystem model the dump loads are constituted by a series of resistors that are connected/disconnected to the systems by a PID controller keeping the system frequency at $50 \mathrm{~Hz}$. As already highlighted, the functioning modelling of the dump load is the main achievement of this first step implementation of the new approach with regard to the E4G project since it is first step for to the implementation and analysis of the dump load-battery pack coupling.

At the moment the model is capable of simulating the dynamic behaviour as regards the power flows among the system components, and to show the frequency trend during the functioning as well.

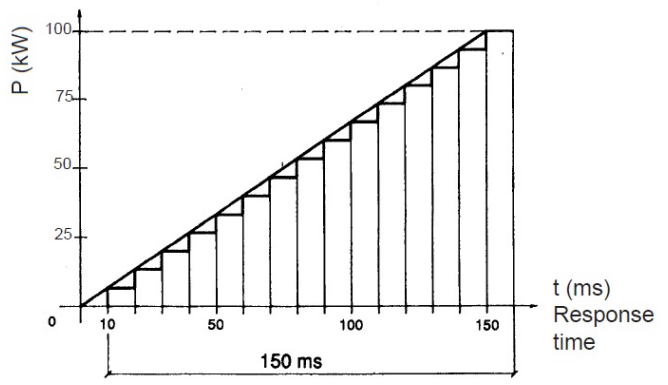

Fig. 11 Dump loads characteristic curve

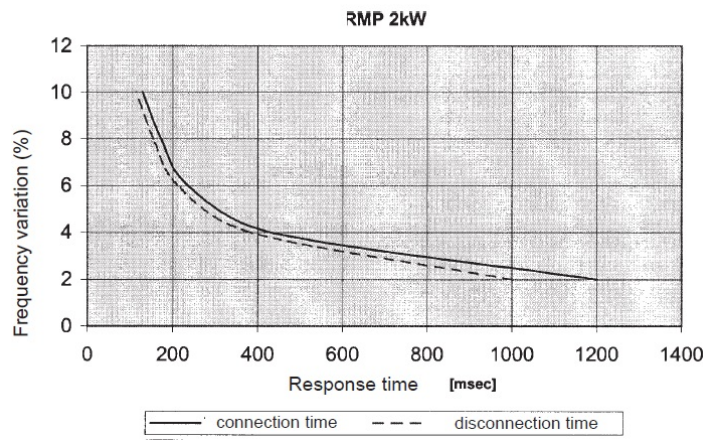

Fig. 12 Dump loads recovery time
We carried out an early validation of the model based on the on-site metering of the functioning system: Fig. 13 shows the metered power flows with 1 minutes average data storing for the synchronous generator, user loads and dump loads, Fig. 14 we report the resulting model profiles of the same power flows by considering as input data of the model, the time series of the generator power injection $\left(P_{\text {gen }}\right)$ and the user loads $\left(P_{\text {load }}\right)$. These time series are the input data for the ideal controlled source of the SimPowerSystem building blocks that then provides the profiles reported in Fig. 14 by simulating the electromechanical behavior of the functioning system.

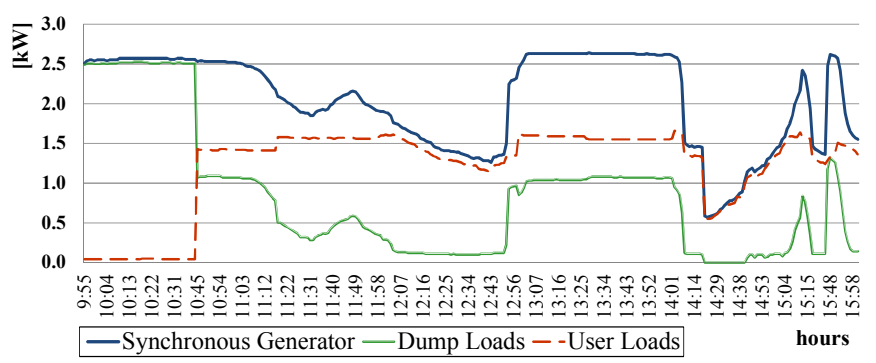

Fig. 13 Metered power flows of October 22, 2014 for the actual power supply system of the school

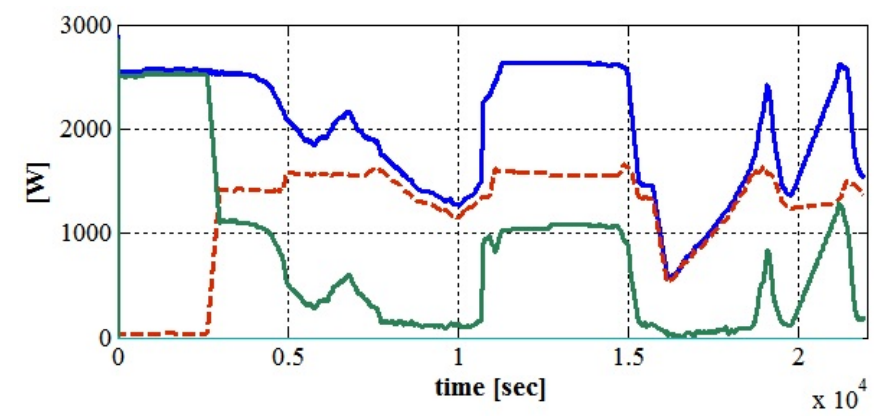

Fig. 14 Power profiles resulting from the system functioning simulation

The validation results highlight the proper operating of the model as regards: (i) the synchronous generator and user loads models that set appropriate voltage and current in order to impose the input data of the power flows profiles, and (ii) the dump load model that operates correctly in order to absorb the difference between the injected power by the generator and the required power by the user loads.

Further simulations are performed in order to highlight the capabilities of the model. Fig. 15 refers to a simulation with a simple load profile with two power steps, while Fig. 16 refers to a more realistic generator and user load profiles that have a number of power steps and ramps. Considering the load profiles, the dump loads operate in such a way as compensate for the excess energy. Moreover, when positive (negative) power steps occur in the user loads, the generator reacts providing (absorbing) 
power thus decreasing (increasing) the frequency. This can be recognized by means of the frequency trends that also highlight the intervention of the dump loads according to the PID control in order to restore the nominal frequency.

In our opinion the new approach for system simulation has novel elements both with regard to energy analyses and power stability analyses. Indeed, it computes power flows within a medium time period allowing energy analyses to be performed as regards system components performances, efficiency, life-span analysis, etc. Moreover, thanks to the possibility of monitoring variables that typically describe system dynamics (i.e. in this firststep model implementation the system frequency), it allows the system control logics to be analysed (i.e. in this case the PID operation) and hence the consequences to be studied both on the system stability and the energy performances.
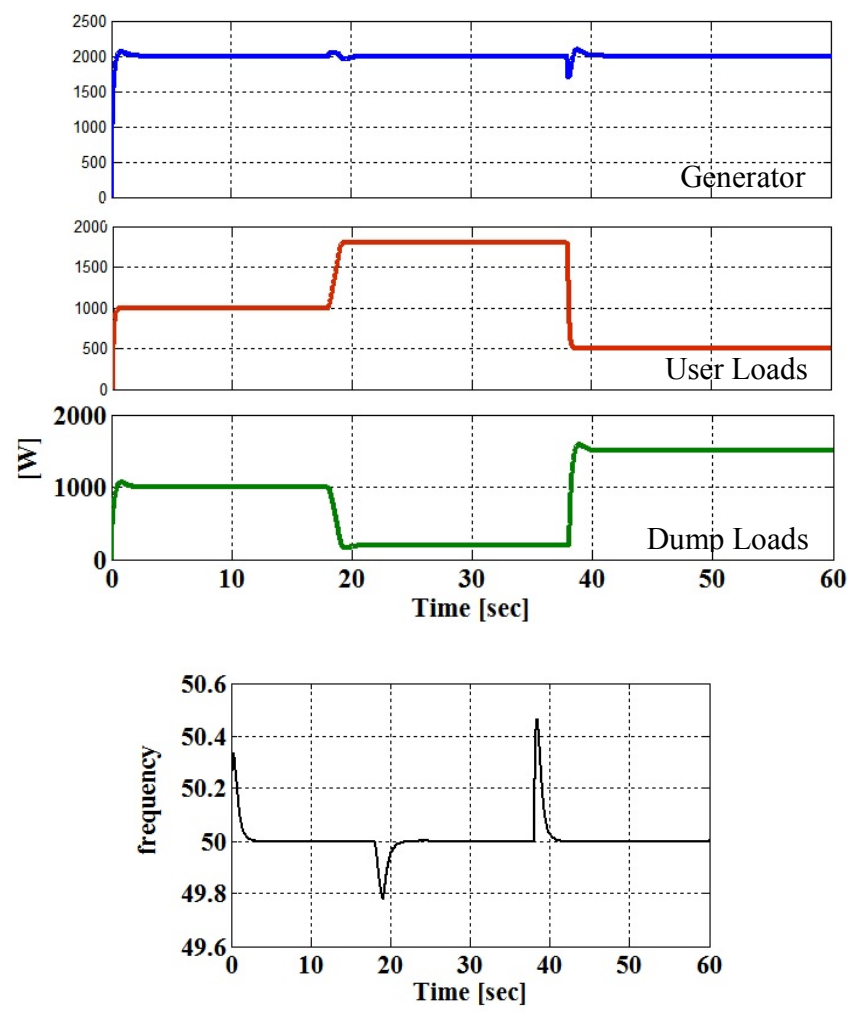

Fig. 15 Model outputs for "steps load profile": active power profiles (on top), frequency trend (below)

\section{CONCLUSION}

The paper is aimed at an introduction of the project Energy4Growing that addresses the improvement of the power supply service of the Ngarenanyuki secondary school (Tanzania) with a hybrid micro-grid. Firstly the results of the functioning metering of the actual school power supply system (run-off-river MHP plant with dump loads) are described, allowing to understand the current school consumption pattern. Then a new approach is introduced that addresses the simulation of the electro-mechanical operation and dynamic behavior within an off-grid power system with respect to perturbation in the power injections from generators and loads. The models development of the synchronous generators, user loads and static converters is described, and accordingly the model of the actual school power system is set up in the MATLAB SimPowerSystem. In particular the focus is on the setting up of the dump loads model. The performed simulations highlight the potentiality of the new approach in integrating the aspects of energy stability analyses and power stability analyses aimed at better supporting the design process of off-grid power supply systems.
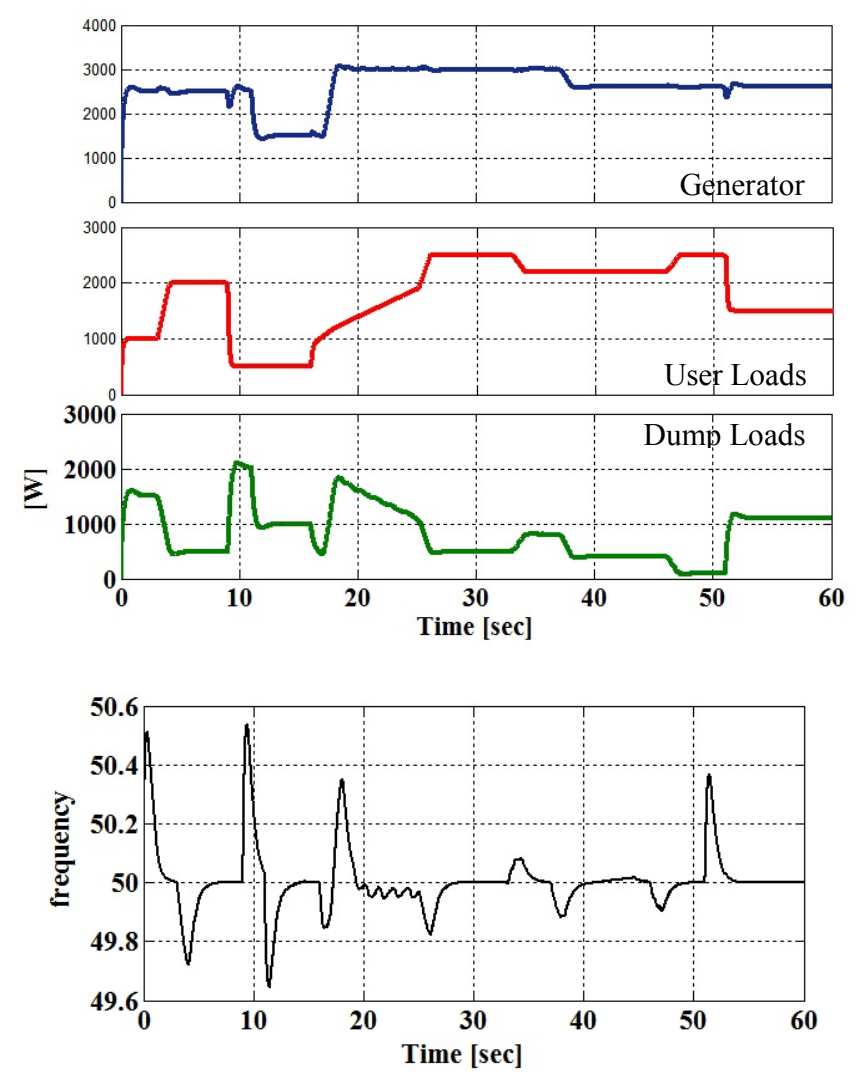

Fig. 16 Model outputs for "realistic load profile": active power profiles (on top), frequency trend (below)

\section{REFERENCES}

[1] IEA, World Energy Outlook 2014. OECD Publishing, 2014, p. 748.

[2] S. Mandelli, J. Barbieri, L. Mattarolo, and E. Colombo, "Sustainable energy in Africa: A comprehensive data and policies review," Renew. Sustain. Energy Rev., vol. 37, pp. 656-686, Sep. 2014.

[3] E. Colombo, D. Masera, and S. Bologna, "Renewable Energies to Promote Local Development," in Renewable Energy for Unleashing Sustainable Development, E. Colombo, S. Bologna, and D. Masera, Eds. Springer International Publishing, 2013, pp. 3-25. 
[4] M. Welsch, M. Bazilian, M. Howells, D. Divan, D. Elzinga, G. Strbac, L. Jones, A. Keane, D. Gielen, V. S. K. M. Balijepalli, A. Brew-Hammond, and K. Yumkella, "Smart and Just Grids for sub-Saharan Africa: Exploring options," Renew. Sustain. Energy Rev., vol. 20, pp. 336-352, Apr. 2013.

[5] B. K. Blyden and W. J. Lee, "Holistic Approach for Grid Interconnection in Africa," in Inaugural IEEE PES 2005 Conference and Exosition in Africa, 2005, no. July, pp. 11-15.

[6] S. C. Bhattacharyya, "Energy access programmes and sustainable development: A critical review and analysis," Energy Sustain. Dev., vol. 16, no. 3, pp. 260-271, Sep. 2012.

[7] B. Tenenbaum, C. Greacen, T. Silyambalapitiya, and J. Knuckles, From the Bottom Up. How small power producers and mini-grids can deliver electrification and renewable energy in Africa. Directions in Development. Washington DC: World bank, 2014, p. 421.

[8] HOMER Energy LLC, "Homer Energy," 2014. [Online]. Available: $\quad$ http://www.homerenergy.com/index.html. [Accessed: 04-Apr-2014]

[9] T. Khatib, A. Mohamed, K. Sopian, and M. Mahmoud, “A New Approach for Optimal Sizing of Standalone Photovoltaic Systems,” Int. J. Photoenergy, vol. 2012, pp. 1-7, 2012.

[10] R. Ramakumar, P. S. Shetty, and K. Ashenayi, "A Linear Programming Approach to the Design of Integrated Renewable Energy Systems for Developing Countries," Energy Conversion, IEEE Trans., vol. EC-1, no. 4, pp. 18-24, 1986.

[11] M. a. Elhadidy and S. M. Shaahid, "Parametric study of hybrid (wind + solar + diesel) power generating systems," Renew. Energy, vol. 21, no. 2, pp. 129-139, Oct. 2000.

[12] S. Mandelli, E. Colombo, A. Redondi, F. Bernardi, B. B. Saanane, P. Mgaya, and J. Malisa, "A small-hydro plant model for feasibility analysis of electrification projects in Rural Tanzania," 2013 IEEE Glob. Humanit. Technol. Conf., pp. 1116, Oct. 2013.

[13] E. Tedeschi, J. Sjolte, M. Molinas, and M. Santos, "Stochastic Rating of Storage Systems in Isolated Networks with Increasing Wave Energy Penetration," Energies, vol. 6, no. 5, pp. 2481-2500, May 2013.

[14] G. G. Moshi, M. Pedico, C. Bovo, and A. Berizzi, "Optimal generation scheduling of small diesel generators in a microgrid," 2014 IEEE Int. Energy Conf., pp. 867-873, May 2014.

[15] G. Bekele and G. Tadesse, "Feasibility study of small Hydro/PV/Wind hybrid system for off-grid rural electrification in Ethiopia," Appl. Energy, vol. 97, pp. 5-15, Sep. 2012.
[16] A. Ghasemi, A. Asrari, M. Zarif, and S. Abdelwahed, "Technoeconomic analysis of stand-alone hybrid photovoltaic-dieselbattery systems for rural electrification in eastern part of IranA step toward sustainable rural development," Renew. Sustain. Energy Rev., vol. 28, pp. 456-462, Dec. 2013.

[17] R. B. Oliva, "Simulation and measurement procedures for effective isolated wind and hybrid system development in south Patagonia," Energy Sustain. Dev., vol. 12, no. 2, pp. 17-26, Jun. 2008.

[18] a. T. D. Perera, R. a. Attalage, K. K. C. K. Perera, and V. P. C. Dassanayake, "A hybrid tool to combine multi-objective optimization and multi-criterion decision making in designing standalone hybrid energy systems," Appl. Energy, vol. 107, pp. 412-425, Jul. 2013.

[19] J. L. Bernal-Agustín, R. Dufo-López, and D. M. Rivas-Ascaso, "Design of isolated hybrid systems minimizing costs and pollutant emissions," Renew. Energy, vol. 31, no. 14, pp. 2227 2244, Nov. 2006.

[20] N. Agarwal and A. Kumar, "Optimization of grid independent hybrid PV-diesel-battery system for power generation in remote villages of Uttar Pradesh, India," Energy Sustain. Dev., vol. 17, no. 3, pp. 210-219, Jun. 2013.

[21] J. a. Cherni, I. Dyner, F. Henao, P. Jaramillo, R. Smith, and R. O. Font, "Energy supply for sustainable rural livelihoods. A multi-criteria decision-support system," Energy Policy, vol. 35, no. 3, pp. 1493-1504, Mar. 2007.

[22] M. Amin, M. K. Zadeh, J. A. Suul, E. Tedeschi, M. Molinas, and O. B. Fosso, "Stability analysis of interconnected AC power systems with multi-terminal DC grids based on the Cigré DC grid test system," in IET 3rd Renewable Power Generation Conference, 2014.

[23] J. Rocabert, A. Luna, F. Blaabjerg, and I. Paper, "Control of Power Converters in AC Microgrids," vol. 27, no. 11, pp. 4734-4749, 2012.

[24] K. De Brabandere, S. Member, B. Bolsens, J. Van Den Keybus, A. Woyte, and J. Driesen, "A Voltage and Frequency Droop Control Method for Parallel Inverters," vol. 22, no. 4, pp. 1107-1115, 2007.

[25] J. C. Vasquez, J. M. Guerrero, S. Member, A. Luna, P. Rodríguez, and R. Teodorescu, "Adaptive Droop Control Applied to Voltage-Source Inverters Operating in GridConnected and Islanded Modes," vol. 56, no. 10, pp. 40884096, 2009.

[26] IREM, "Electronic regulators and electric control boards," 2014. [Online]. Available: http://www.irem.it/ENG/index.php. [Accessed: 15-Nov-2014]. 